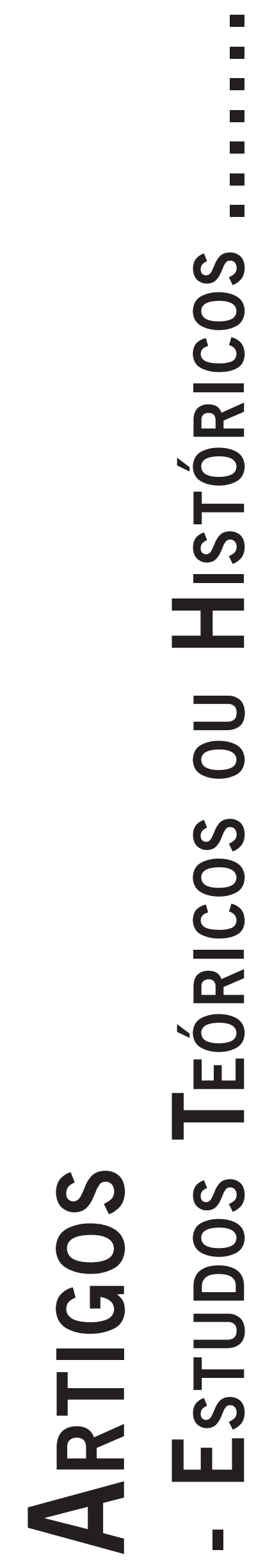




\title{
A PSICOLOGIA INDICADA POR KIERKEGAARD EM ALGUMAS DE SUAS OBRAS ${ }^{1}$
}

\author{
The Kierkegaard's Psychology Indicated in Some of His Books
}

La Psicología Presente en Algunas Obras de Kierkegaard

Myriam Moreira Protasio

\begin{abstract}
Resumo: A possibilidade de associar o pensamento de Kierkegaard com a psicologia, embora não seja nova, merece esclarecimentos. Este trabalho pretende dar um passo neste sentido, ao considerar a obra de Kierkegaard como um todo e, em especial, três de suas obras, que trazem em seu subtítulo palavras como: reflexão psicológico-demonstrativa; exposição cristã-psicológica; ensaio em psicologia experimental. Tentarei articular o que se pode compreender por psicologia a partir da determinação do filósofo em associar a ciência psicológica com "conhecimento hábil da vida humana e simpatia com seus interesses". O que importa para Kierkegaard é a vida de cada um em sua tarefa de justificar-se, eternamente, como o existente que ele mesmo é. Seu esforço se dirige para uma retomada da vida em seu acontecimento, enquanto a particularidade da vida de cada um, a minha vida, que sempre se relaciona com a universalidade que é o viver mesmo. O trabalho pretende dar relevo ao modo como o projeto kierkegaardiano de psicologia associa-se a uma fenomenologia, ao apontar para a impossibilidade de compreendermos os seus tipos existenciais a partir de categorias universais e, por fim, anunciar a relação entre uma psicologia de Kierkegaard e a possibilidade de uma transformação existencial.
\end{abstract}

Palavras-chave: Sören Kierkegaard; Psicologia clínica; Filosofia da existência; Fenomenologia.

Abstract: The possibility of associating the thought of Kierkegaard with psychology, although not new, deserves clarification. This paper aims to take a step in this direction by considering the work of Kierkegaard as a whole and, in particular, three of his works, which bring words like: A simple psychologically orienting deliberation; A Christian psychological exposition; essay in experimental psychology. Since Kierkegaard has associated a Psychological science with "skillful knowledge of human life and friendliness with their interests", the work will try to articulate what is this psychology. What matters, to Kierkegaard, is the each one life in its task to eternally justifying himself or herself. Your effort is directed toward taking again the life while the peculiarity of the each one life, my life, that always relates to the universality of the life. The work will highlight the way that Kierkegaardian's psychology project is associated with a phenomenology, by pointing the inability to understand the existential types from universal categories. Finally, this text announces the relationship between Kierkegaard's psychology and the possibility of an existential transformation.

Keywords: Sören Kierkegaard; Clinical psychology; Existential philosophy; Phenomenology.

Resumen: La posibilidad de asociar el pensamiento de Kierkegaard con la psicología, aunque no es nuevo, merece una aclaración. Este trabajo pretende dar un paso en esta dirección al considerar la obra de Kierkegaard en su conjunto y, en particular, tres de sus obras, que tienen en sus palabras de subtítulos: reflexión demostrativo-psicológica; una exposición cristiano-psicológica; un ensayo de psicología experimental. Partiendo de la determinación de Kierkegaard, que asocia la ciencia psicología con "el conocimiento experto de la vida humana y la amabilidad de sus intereses", el texto va a tratar de articular lo que se puede entender como su psicología. Lo que importa para él es comprender la vida de cada uno en su tarea de encontrar su propia justificación eterna. Su esfuerzo se dirige hacia una reanudación de la vida mientras la peculiaridad de la vida de cada uno, mi vida, siempre referida a la universalidad de la vida. El trabajo hará hincapié que su proyecto de psicología se asocia a una fenomenología, al apuntar a la incapacidad de comprender sus tipos existenciales con base en categorías universales. Por último, va anunciar la relación entre la psicología de Kierkegaard y la posibilidad de una transformación existencial. Palabras clave: Sören Kierkegaard, Psicología clínica, La filosofía existencial; Fenomenología.

Psicologia é o que precisamos e, acima de tudo, conhecimento hábil (expert) da vida humana e simpatia com seus interesses. Kierkegaard (Pap. V B 53, p. 119)

\footnotetext{
${ }^{1}$ Apresentado no III Congresso Sul-Brasileiro de Fenomenologia \& I Congresso Brasileiro de Psicologia \& Fenomenologia, realizado na Universidade Federal do Paraná (UFPR), entre os dias 12 e 14 de agosto de 2013.
}

\section{Introdução}

A possibilidade de associar o pensamento de Kierkegaard com a psicologia, embora não seja nova, merece esclarecimentos. Este trabalho pretende dar um passo neste sentido, entendendo que uma investigação deste tipo exige vários vieses de aproximação. Para este momento elegeu-se buscar esclarecimentos tendo como 
ponto de partida alguns textos de Kierkegaard que fazem referencia explicita à palavra psicologia.

Vou começar ressaltando a presença da psicologia no pensamento de Kierkegaard, de forma a nos ambientarmos com o que está em questão. Psicologia foi a palavra escolhida por Kierkegaard para designar o ramo de investigação da vida humana particular, ou melhor, da vida singular, em tensão com os ramos investigativos que pensavam a vida humana como um universal. Kierkegaard (1844/2010a) escreve, na voz do pseudônimo Vigilius Haufniensis o livro Conceito de angústia, cujo subtítulo diz: uma simples reflexão psicológico-demonstrativa, direcionada a problema dogmático do pecado hereditário. Neste livro ele apresenta o ramo investigativo da Psicologia em contraste com os ramos da Ética e da Dogmática, buscando dar relevo ao problema metafísico em questão: se a investigação acontece por via da dogmática, a relação com a vida humana é de desinteresse dialético, pois, uma vez dado o ponto de partida, o restante da investigação prossegue de forma abstrata e sistemática e a vida mesma queda esquecida; se, por outro lado, a investigação acontece por via da Ética acontece o oposto: o ponto de partida é menos importante que o ponto de chegada. No entanto, este ponto de chegada é um ideal, sem interesse se a vida humana tem ou não condição de atingi-lo. Assim, se a investigação da vida humana segue o ramo da ética, a atmosfera requerida é julgadora; se por via da dogmática, a atmosfera é a do desinteresse.

A investigação psicológica ofereceria uma terceira via. No entanto, aponta Haufniensis, a Psicologia precisaria ir além do que ela vinha fazendo até então: escrutinando a vida humana, observando-a e descrevendo-a, com o prejuízo de que estas representações não passassem de sombra do que fosse, realmente, a vida humana. Que psicologia seria esta?

No inicio do século XIX a ciência não era, ainda, o que veio a se tornar no século XX, uma especialidade das ciências físicas e naturais, mas ciência era sinônimo de filosofia e de saber especulativo, construído sobre a pressuposição da identidade entre sujeito cognoscente e objeto conhecido, entre subjetivo e objetivo, ou seja, tendo o sujeito com ponto de partida de todo conhecimento. Segundo Brentano (1874/1995), com a modernidade houve um encolhimento do domínio da psicologia, assim como do conceito de vida e do conceito de alma. O que encontramos é a ideia de alma como um conjunto de leis e princípios que regula o funcionamento dos fenômenos internos, pensados a partir de um paralelismo com os fenômenos externos. Ele afirma: "Na linguagem moderna, compreendemos efetivamente por alma o substrato substancial de representações (...) nos habituamos a chamar de alma, por exemplo, o substrato substancial de uma sensação, de uma imagem, de uma lembrança, de uma esperança ou de um medo, de um desejo ou de uma repulsão" (Brentano, 1874/1995, p. 5). A partir da modernidade a psicologia passa a designar um modo do conhe- cimento e vai se transformando, praticamente, em teoria do conhecimento. É nestes termos que Husserl (1901/2007) refere-se ao Psicologismo, momento em que a psique passa a ser a economia do conhecimento, mais do que a economia da alma e vai, paulatinamente, se transformando em neurologia, fisiologia, em relação de corpo e alma.

Este modo de pensar é expresso pelo pensamento de Hegel e de seus seguidores. Em um artigo de 2010, Alvaro Valls e Jasson Martins referem-se ao tratamento dado por Hegel à psicologia dentro de seu sistema, citando o modo como Hegel define, na Enciclopédia, o que seria o objeto da psicologia: seu ser (em si) e a produção de si mesmo (ser para si). Ela deve estudar o espírito separado de suas funções anímicas, de sua materialidade, pensando a consciência como o que se localiza acima da natureza e se individualiza no homem enquanto saber da sua totalidade substancial, ou seja:

[...] as faculdades ou modos gerais de atividade do espírito como tal, intuir, representar, recordar, etc. desejos, etc., de uma parte, sem o conteúdo, que segundo o fenômeno se encontra no representar empírico e também no pensar como no desejo e na vontade; de outra parte, sem as formas nas quais está na alma como determinação natural, e na consciência mesma, como um objeto seu, para ela disponível. (Hegel, 1995, $\S 440$, citado por Valls \& Martins, 2010, p. 17)

Havia, ainda, uma Psicologia, contemporânea a Kierkegaard que estava sendo idealizada e desenvolvida nos laboratórios de investigação psicofísica das universidades alemãs e inglesas. Estes estudos soavam, à época, como sólidos, fortes, invencíveis, eternos, absolutos, ou seja, como guardando consigo todas as possibilidades passadas, presentes e futuras do espírito, ou seja, da existência humana. Kierkegaard, que não conheceu Darwin, teve contato com o pensamento do pré-darwinista JeanBaptiste de Lamarck, cuja tese principal, explicitada em sua tese dos caracteres adquiridos, era que o ambiente terrestre sofre modificações constantes e as suas alterações estruturais forçam os seres que nele vivem a se transformarem para se adaptarem ao novo meio, de forma que estas transformações são herdadas pelas gerações seguintes, fazendo surgir espécies mais evoluídas.

Tanto no projeto de Psicologia pensado por Hegel, quanto na Psicologia desenvolvida nos laboratórios, o que se perdia de vista era a vida humana, cotidiana e concreta. Kierkegaard, sob a voz de muitos dos seus pseudônimos - Haufniensis (2010a), Anti Climacus (1849/2008a e 2010b) e Constantin Constantius (1843/2009) - estranha este modo de voltar-se para a vida humana e seus interesses. Esses últimos são, para ele, explicitamente, aquilo que deve interessar a uma Psicologia. A psicologia aparece, com Kierkegaard, como investigação acerca da vida humana singular em tensão com a vida humana enquanto um universal. Cabe, então, perguntar quais seriam as 
bases para este ramo investigativo? Para responder a esta pergunta é preciso acompanhar o modo como Kierkegaard desdobra o problema, o que farei ressaltando a presença da psicologia em alguns de seus textos.

Nos subtítulos dos textos sobre angústia, repetição e desespero aparecem associadas palavras tais como: reflexão psicológico-demonstrativa; exposição cristã-psicológica; ensaio em psicologia experimental. Estes subtítulos dão prova de que a psicologia já fazia parte do rol de interesse do filósofo dinamarquês. Mas, o que Kierkegaard está pretendendo quando se refere à psicologia, conforme aparece nos subtítulos destes livros? Qual seria o projeto de psicologia colocado em cena pelos pseudônimos autores destes textos? De que formas se relacionam a opção do filósofo pela comunicação indireta, que inclui a autoria pseudonímica, e a psicologia tal como pensada por ele? Começarei a desdobrar estas questões tecendo considerações acerca da comunicação indireta.

\section{A comunicação indireta}

Umas palavras iniciais sobre a comunicação indireta. Sabe-se que Kierkegaard tem uma vasta produção, grande parte dela assinada por pseudônimos. Há uma tendência, entre os leitores de Kierkegaard, de associar a comunicação indireta com estes textos pseudonímicos. Mas, tomando o esclarecimento prestado por Kierkegaard (1859/1986) no livro Ponto de vista explicativo da minha obra como escritor, onde ele organiza o conjunto de sua obra, encontra-se a seguinte divisão - obras estéticas (os textos pseudonimicos); uma obra intermediária (Postscripitum definitivo e não científico a Migalhas Filosóficas, 1846/2008b); e obras religiosas (os discursos edificantes, assinados por ele). Pode-se concluir, a partir deste esclarecimento, que a obra como um todo está a serviço da comunicação indireta. Mas o que significa isto e qual o seu propósito? Ele próprio responde: o propósito total da obra é alcançar o homem no lugar em que ele se encontra e esforçar-se por compartilhar sua disposição. Começando deste ponto, assumindo o mesmo pathos do leitor, usar a comunicação indireta, ou seja, as várias obras para tentar tirar este homem da ilusão de ser o que em ato ele não é.

Duas coisas merecem ser ressaltadas, no que diz respeito à comunicação indireta, ou seja, ao modo como Kierkegaard usa sua obra para comunicar-se com seu leitor. A primeira delas é que não há, na obra, nenhuma referência a uma coletividade, a uma impessoalidade, mas, ao contrário, Kierkegaard acena que cada texto seu se dirige a um homem em particular ou, como ele prefere, ao "meu leitor". Desta forma ele quer acentuar que a sua comunicação não foi feita em um púlpito e nem em um palanque e não se dirige a nenhuma multidão abstrata; e que também não se constituiu em um grande sistema. A comunicação pretendida por meio de sua obra queria falar diretamente ao indivíduo, ou seja, para ser alcançada ela dependia de um ato individual, $\mathrm{o}$ ato de ler o texto.

A segunda coisa a ser ressaltada é que a grande ilusão a que Kierkegaard se refere relaciona-se o horizonte histórico próprio de seu tempo, o cristianismo. O cidadão dinamarquês, por viver em um país cristão que tinha a igreja filiada ao estado, acabava tendo uma relação de neutralidade indiferente com a tarefa propriamente dita de ser um cristão. Sendo cristãos desde o nascimento, os cidadãos não precisavam fazer mais do que cumprir os compromissos de domingo, ou seguirem os preceitos declarados nos púlpitos. Esta indiferença aparecia, também, nas academias, uma vez que a religião ficava submetida aos grandes sistemas teológicos ou filosóficos.

Para fazer frente ao problema da diferença entre os modelos idealizados, seja nos sistemas filosóficos ou nas instituições cristãs, e a vida mesma, a obra de Kierkegaard assume, com sua comunicação indireta, uma posição negativa, ou seja, opta por tonalidades as mais diversas, de modo a se relacionar com a própria situação da existência, que é marcada por indeterminação e liberdade e só acontece de forma singular. É por esta perspectiva que podemos entender a tensão, colocada por Kierkegaard, entre ser cristão (de nome) e tornar-se cristão (de fato), o que diz respeito ao caráter de mobilidade da existência, que é sempre livre, ou seja, indeterminada. O indivíduo (o cristão) precisa conquistar a si mesmo, ou seja, sendo cristão de nome precisa tornar-se cristão de fato. O mesmo vale para a condição humana - sendo humano de nome, o homem precisa conquistar sua humanidade.

Assim, toda a obra de Kierkegaard, ao ser lida, pretende alcançar o indivíduo, o seu leitor, mas posiciona-se de modo indireto, um posicionamento de ironia pode-se dizer. O que significa isto? Que o propósito da obra é posicionar-se na retaguarda, não afirmar nenhuma verdade, mas tentar garantir a possibilidade de transformação, a possibilidade de que o leitor saia do lugar em que está, da ilusão em que existe, pensando ser o que em ato, efetivamente, não é, e venha a sê-lo, realizando o encontro entre o exterior e o interior, o imanente e o transcendente, alcançando transparência acerca de si mesmo e de sua situação. 
Com este posicionamento, este tipo de comunicação, Kierkegaard está fazendo frente ao tipo de comunicação vigente em seu tempo, a comunicação dos grandes sermões religiosos e dos grandes sistemas acadêmicos, todos descendentes do sistema hegeliano. Com relação tanto à filosofia quanto à teologia de seu tempo o filósofo entendia que um ataque direto conseguiria, no máximo, fortalecer as resistências. Assim cada texto seu, e a obra como um todo, "se relaciona com o cristianismo, com o problema do tornar-se cristão, com intenções polemicas diretas e indiretas contra a formidável ilusão que é a cristandade, ou a pretensão de que todos os habitantes de um país são tais quais, cristãos" (Kierkegaard, 1986. p. 22).

A grande ilusão é a de que já se nasce determinado, o que aparece no contexto do cristianismo pela determinação de já se nascer cristão. A comunicação indireta tem seu fundamento nesta ilusão, e está a serviço de uma mobilização existencial: o si mesmo precisa se conquistar, não é dado previamente, o que exige uma mobilização entre os diferentes estádios existenciais, ou seja, entre as várias possibilidades de existir, que ele apresenta ao longo da obra como sendo os modos estético, ético e religioso de existir. A mobilidade entre esses estádios deve ser pensada, no entanto, a partir da perspectiva da possibilidade e nunca da necessidade, ou seja, tornar-se si mesmo (tornar-se cristão ou tornar-se humano) acontece no âmbito das possibilidades, o que significa dizer que não está garantido e exige um salto, uma decisão no âmbito da existência mesma.

Uma vez que a mobilização entre os estádios dificilmente adviria de uma mera articulação ético-teórica, o que Kierkegaard pretende com a comunicação indireta é chegar até o leitor no lugar em que este se encontra e, pareando-se com ele, manter aberto o espaço da possibilidade. A chave para o que está em questão aqui é o tema da liberdade, ou seja, a mobilidade entre os estádios constitui-se em possibilidade e nunca em necessidade.

Como tentei mostrar, o que importa para Kierkegaard é a vida de cada um enquanto tarefa de justificar-se, eternamente, como o existente que ele mesmo é. Seu esforço se dirige para uma retomada da vida em seu acontecimento enquanto a particularidade da vida de cada um, a minha vida, que sempre se relaciona com a universalidade que é o viver mesmo. O caráter particular da existência aparece na obra de Kierkegaard tanto no modo como ele se dirige ao "seu leitor", ou seja, a um leitor particular, quanto na descrição de modos de existir, sempre singulares. É este projeto de encontrar um homem em particular, de comunicar-se com cada homem que, segundo entendo, abre espaço para a psicologia no pensamento de Kierkegaard. A partir de agora tentarei desenvolver como esta psicologia encontra materialidade em alguns de seus textos. Começarei com o texto da angústia.

\section{A psicologia no contexto de $O$ Conceito de Angústia}

O texto Conceito de angústia traz o seguinte subtítulo: uma simples reflexão psicológico-demonstrativa, direcionada a problema dogmático do pecado hereditário, de Vigilius Haufniensis (Kierkegaard, 1844/2010a). Embora a obra anuncie uma investigação sobre o conceito angústia, o que vem em seguida é uma reflexão psicológico-demonstrativa. O tema será o pecado hereditário, mas a reflexão terá cunho psicológico. Ou seja, o conceito angústia, embora apareça associado ao problema dogmático do pecado hereditário, não será tratado no campo do conhecimento dogmático (teológico) ou metafísico, mas no campo da vida, por isso será tratado psicologicamente, ou seja, estando sempre referido ao indivíduo singular. Assim, o pecado não se refere, do ponto de vista da psicologia, a algo já posto dogmaticamente como principio e nem se refere ao ideal de uma vida sem pecado a ser conquistada, mas refere-se à própria existência cujo fundamento é liberdade.

Haufniensis mostrará que o estado psicológico do qual emerge a possibilidade do pecado, ou seja, ação do homem, é angústia, e este será o objeto de uma ciência psicológica. Angústia é a atmosfera ou o estado que define a situação de liberdade em que se encontra todo homem. Somente a angústia anuncia a existência em sua caracterização de precariedade, de indeterminação, de abertura e de liberdade. À psicologia não cabe o pecado em si, ou seja, a ação humana, mas o estado em que a existência se mostra, sempre em relação à possibilidade, cuja forma é angústia. Angústia é, então, o estado próprio da existência.

Partindo dessas considerações, o que se tem é que cada determinação existencial, cada estado, denuncia um modo específico do existente lidar com sua caracterização de liberdade. Por isso Haufniensis aponta, neste livro, que o conceito angústia precisa ser pensado por meio do pecado e daquele que, na era cristã, aparece como o primeiro pecador, Adão. Adão é o homem por meio do qual se dá a concretização do pecado. E o estado do qual o pecado surge é angústia, ou seja, conforme definido por Haufniensis, possibilidade para as possibilidades. Adão incorre em erro (pecado), ao sair do estado de ignorância ao não se saber livre, e agir conforme sua vontade, distanciando-se de uma vontade e de uma determinação que lhe é exterior. Mas não se pode descobrir a possibilidade de agir por vontade própria a partir de um nada. Esta possibilidade precisa já ter estado presente, disponível, ainda que sob a forma de uma indeterminação, um nada cuja materialidade era apenas angústia. Assim Haufniensis coloca a angústia como o solo, o fundamento da existência humana, o estado de onde pode advir o pecado, ou seja, a ação livre do homem.

À psicologia, segundo Haufniensis, interessa esta possibilidade e o estado de onde ela surge, ou seja, a angústia. É este o estado de onde provém todo modo de 
existir. Por isso este estado é de interesse da psicologia. Como aparece na epígrafe inicial deste texto, precisamos de psicologia, mas a psicologia que precisamos é aquela que tem simpatia com os interesses do homem, ou seja, interessa-se pela paixão que o anima, a qual aparece sob forma de angústia. Em termos da comunicação indireta e de sua relação com uma psicologia, o tema deste texto de Haufniensis é a liberdade, ou seja, aquilo que determina a existência como possibilidade para as possibilidades. Á medida em que se compreende a existência humana como fundada na liberdade, e não em determinações previas, sejam elas de ordem biológica, religiosa ou social, a angústia aparece como o solo onde se desenha o interesse que funda o fazer humano, aquilo que pode servir de lastro para sua existência.

Este texto da angústia traz muitas outras contribuições para se pensar uma Psicologia a partir de Kierkegaard, mas por hora ficaremos por aqui, de forma a tomarmos outro texto em que aparece em discussão a questão de uma justificativa para a existência, ou seja, da possibilidade de se encontrar este lastro que dê sentido à existência.

\section{A psicologia no texto A Doença Mortal}

Tomemos o texto: A doença mortal, ou do desespero e o pecado: uma exposição cristã-psicológica para edificar e despertar, escrito em 1849 e assinado por outro pseudônimo, Anti Climacus (Kierkegaard, 1849/2008 e 2010b). Ainda o cristianismo e o pecado, e ainda uma exposição psicológica, mas, agora, para edificar e despertar, e com um elemento novo, que associa desespero com doença mortal. Na abertura do texto Anti Climacus estabelece a relação entre cristianismo, edificação e inquietação. Como no texto da angústia, o autor assinala que o horizonte histórico é o do cristianismo, ou seja, diferentemente do horizonte histórico grego, com suas determinações temporais e finitas, aqui o elemento eterno deve ser levado em consideração. O desespero caracteriza a existência quando o eterno adentra o tempo, pois agora o eu não é uma mera relação entre corpo e alma, entre imanência e transcendência mas é uma tensão entre eterno e temporal, entre finito e infinito, entre possível e necessário.

O que significa dizer que o desespero caracteriza a existência enquanto tensão entre os elementos que a constitui? Anti Climacus expõe três tipos possíveis de desespero, que se relacionam com o elemento vontade: querer ser si mesmo, não querer ser si mesmo e ignorar ser um si mesmo. Cada um destes "tipos" aparece por meio dos estados psicológicos expostos pelo autor e que se constituem em modos possíveis do existente assumir a tensão que ele é. Há um propósito nesta exposição, não esqueçamos, qual seja: despertar e edificar. Só pode despertar quem está dormindo, ou seja, quem não se sabe desespe- rado. No entanto, uma vez desperto, o eu descobre que ser desesperado é sua condição existencial, por isso a inquietação é a atmosfera própria daquele que existe fora da ignorância, daquele que se sabe tensão. Assim, todo e qualquer modo de viver se constitui numa tentativa de escapar desta tensão e, paradoxalmente, já se constitui como um modo específico de ser esta tensão. Com isso o que aparece, mais uma vez, é a liberdade do homem, que pode existir conforme as condições de sua própria existência, que é tensão constante, ou pode constituir-se em existência desesperada, ou seja, em tentativas constantes de estabelecer o modo da relação.

E o que dizer da edificação? Tal como no texto da angústia, a edificação se filia à perspectiva da transformação, da saída de um estado a outro, da saída da ilusão para a transparência. O solo dos dois textos é a fé nos possíveis. Não uma fé instalada fora do mundo e fora do tempo, mas uma entrega ao mundo e às suas possibilidades, ao seu caráter de abertura indeterminada e, ao mesmo tempo, clamante de uma determinação da ordem da necessidade. Edificar-se é mais do que mudar, que sair de um estado a outro. É transformar-se no sentido de encontrar a "sua" necessidade em meio às possibilidades. Não há melhor forma de falar disso a não ser pensando na relação do homem com o eterno, com algo que está para além das determinações do tempo e da finitude, que não pode aparecer na ordem das descrições, mas precisa ser encontrado de forma única, singular, secreta, e não pode ser objetivado, substancializado e transformado em uma identidade universal.

Ora, viver é transformação incessante, mas o que está em questão na situação do desespero é que a transformação pode conquistar um caráter de eternidade, de lastro existencial. Este caráter eterno não se constituirá em uma identidade, mas em um "afinar-se" com o horizonte próprio do seu existir. Mais uma vez o estado da existência não cabe em um conceito e precisa aparecer em meio a tipos possíveis que, em sua individualidade, podem ser compreendidos pela psicologia, uma vez que esta é campo das singularidades ou, pelo menos, da possibilidade de singularizar-se.

O que apresentei aqui é muito pouco frente à complexidade das discussões e das contribuições oferecidas por Anti Climacus para a Psicologia. Sugiro ao leitor interessado que se debruce sobre este texto e encontre estas contribuições. Passarei, agora, a outro texto de Kierkegaard, onde o exercício propriamente dito da psicologia encontra expressão.

\section{A psicologia presente na obra $A$ Repetição}

Vou considerar, ainda, uma terceira obra: A repetição: um ensaio em psicologia experimental, assinada por Constantin Constantius (Kierkegaard, 2009). Nós psicólogos, sabemos muito bem o que significa psico- 
logia experimental - inclui um laboratório de medição, alguns animais ou mesmo pessoas voluntárias, um conjunto de hipóteses, possibilidades de verificação e de generalização. Será o mesmo que o pseudônimo está considerando neste texto? O que quer dizer psicologia experimental para este pseudônimo? Mais uma vez somos, imediatamente, levados para longe de uma explanação teórica ou conceitual. Constantin recorre a Leibniz para dizer que este entendeu o que era repetição quando percebeu que repetição e recordação são a mesma coisa, apenas em direções opostas. Repetição é uma recordação lançada para frente, e recordação é uma repetição voltada para trás (Kierkegaard, 2009, p. 32). A questão da repetição mostra seu parentesco com o tempo, mas não um tempo abstrato, mas o tempo vivido. É a vida que repete.

A recordação é um vestuário usado que, por mais belo que seja, não serve, porque não se cabe nele. A repetição é um vestuário inalterável que assenta firma e delicadamente, não aperta nem flutua. A esperança é uma deliciosa rapariga que se nos escapa por entre as mãos; a recordação é uma bela mulher avançada na idade com quem, no entanto, nunca se está bem servido no momento; a repetição é uma amada esposa de quem nunca se fica farto; porque só do novo se fica farto. (Kierkegaard, 2009, p. 32)

Tais ponderações são o aperitivo de que se serve o pseudônimo Constantin Constantius para discorrer sobre mais um conceito, o da repetição. Mais uma vez só há um modo de se falar do conceito: apresentar o problema da repetição onde ele é, efetivamente, um problema, ou seja, apresentar a vida de alguém em tensão com a repetição, ou melhor, em tensão com a vida, que é repetição incessante. É por meio ao "experimento psicológico", ou seja, ao caráter experimentante da existência de alguns personagens que vem à tona o problema da repetição e sua relação com o tempo. Um jovem apaixonado, que prometera casamento a sua amada, busca a companhia de Constantin em busca de conselhos. Prometeu casamento, mas agora teme casar-se e perder a criatividade apaixonada que lhe veio com o seu estado de paixão. Quer eternizar este estado, quer eternizar a paixão romântica. Constantin, um homem mais velho e experimentado, acredita que pode ajudá-lo e apresenta-lhe as soluções conhecidas: articular um modo da jovem desistir de casar com ele. O problema ganha, então, ares de experimento psicológico, ou seja, da repetição de um experimento já vivido e do qual se pode extrair, hipoteticamente, a certeza de que tudo se repetirá como da primeira vez. Mas, meio ao experimento-vida ele vai colhendo a impossibilidade deste tipo de repetição.

Justo (2009) acentua, em sua introdução à tradução portuguesa do livro A repetição que o novo é debitário do tempo rápido, do tempo que se acelera para dar lugar às novidades. Não se quer a repetição quando se busca sempre o novo. "A fila anda" é um jargão do nosso tempo que pode ilustrar bem este caráter do tempo rápido. O jovem personagem do texto teme o tempo longo, teme a decisão que sugere duração no tempo, qual seja, casar-se com a jovem de quem está apaixonado. Prefere a eternidade romântica do poeta, que garante a permanência do mutável, por meio da recordação. O jovem não quer a repetição na vida, prefere a repetição imaginativa. $\mathrm{O}$ seu conselheiro compartilha da possibilidade da repetição do mesmo.

No entanto na vida experimentante, na vida vivida, este tipo de repetição não tem lugar. A repetição da vida é uma conquista, depende de coragem e de entrega. Não podendo seguir os conselhos de Constantin só resta ao jovem descobrir a "sua medida”, ou seja, a medida da "sua" existência em meio à tensão de sua existência, de onde vai surgindo a "sua" necessidade na situação, aquilo que, silenciosamente, aparece para ele como a decisão a ser tomada. "A repetição é um vestuário inalterável que assenta firma e delicadamente, não aperta nem flutua”, diz Constantin. Não aperta nem flutua por que sua medida não é da ordem do idealizado, imaginado, desejado ou poetizado, mas da ordem da vida mesma, em suas dádivas e exigências, em suas possibilidades e necessidades, em seu caráter finito e infinito. Assim, o jovem sai da repetição poética para a repetição existencial.

O que o "experimento psicológico" mostra é o caráter experimentante da vida, que por não estar previamente determinado, precisa conquistar sua medida. Mais uma vez abre-se o campo da psicologia como ciência do particular, do indivíduo singular, não enquanto uma subjetividade solipsista, mas enquanto existência particular em tensão constante com a ordem de seu mundo, ou seja, com o universal.

Tendo considerado, conforme meu propósito, os três textos pretendidos, tentarei mostrar como o método indireto de Kierkegaard constitui-se num gesto fenomenológico ao buscar encontrar a existência mesma e estabelecer uma relação de interesse para com ela.

\section{Um projeto de psicologia de inspiração Kierkega- ardiana}

Uma Psicologia kierkegaardiana estará lidando com as possibilidades e riscos que caracterizam o existir humano. Estas possibilidades e riscos aparecem, na obra do filósofo, singularizadas nos tipos, nos personagens e nas atmosferas provocadas pelo filósofo em seus escritos. Cada tipo, cada personagem ou atmosfera fala daquela situação específica, ali descrita, mas dirige-se ao leitor, abrindo um vazio em que este pode ver a si mesmo, de forma que o texto está alertando para os riscos e possibilidades do existir do leitor, apontando para a proximida- 
de entre a estória do personagem e a própria existência do leitor, entre a existência particular do personagem e a existência enquanto universalidade, ou seja, enquanto existência de todos os homens.

Portanto parece pertinente considerar o modo como Kierkegaard desenvolve uma fenomenologia, ao apontar para a impossibilidade de compreendermos os tipos existenciais a partir de categorias universais, sejam elas garantidas por um sistema dogmático ou metafísico, ou mesmo submetidas a categorias éticas ou nosológicas. Ele propõe que, em lugar de entendermos os tipos a partir destas categorias, consideremos as tipologias na singularidade de cada tipo. Uma psicologia kierkegaardiana deve realizar este gesto, assim como deve estabelecer uma relação de interesse com os interesses do homem.

Retomemos nossa epígrafe inicial, colhida por Nordentoft (2009) dos Papirer de Kierkegaard: "Psicologia é o que precisamos e, acima de tudo, conhecimento hábil (expert) da vida humana e simpatia com seus interesses". A psicologia de que precisamos vincula-se a um conhecimento da vida humana, ou seja, das condições da vida humana. Conhecer a vida humana significa aqui, conhecer a sua condição, que é indeterminação, abertura, tensão. Estas condições são resumidas por Kierkegaard, por meio dos pseudônimos citados acima, como angústia, repetição e desespero. Conhecer a vida humana é saber que o desespero e a angústia são sua determinação e que, em sue caráter de negatividade, de abertura, a existência guarda sempre a possibilidade da transformação, ou seja, cada modo de existir guarda sempre consigo outras possibilidades.

A possibilidade de transformação é de especial importância para o exercício de uma psicologia clínica (Feijoo, Mattar, Feijoo, Lessa \& Protasio, 2013), considerando que é, justamente, esta atmosfera de negatividade que deve ser assegurada numa relação que se pretende de ajuda, uma vez que o interesse, ou seja, aquilo que une os envolvidos no processo clinico é, justamente, a possibilidade de transformação. A psicologia de que precisamos, portanto, é aquela que simpatiza com os interesses do homem e que se inclina, como o médico no leito do doente, para ouvir a fala da angústia e do desespero, sabendo que é aí, no espaço da fala, que descansa a possibilidade. E que é da possibilidade que pode advir uma transformação.

A psicologia pode espelhar-se no projeto de Kierkegaard, e tomando as indicações de seus textos, assumir uma posição negativa, interessar-se pelo interesse do cliente ao modo deste, e aguardar, pacientemente, que "algo" se dê, que na repetição cotidiana apareça a "sua" necessidade, ou seja, a necessidade do cliente. As aspas servem para dar a medida da possibilidade e do limite do psicólogo, que pode interessar-se, pode esperar pacientemente, pode ser inclusive, um elemento importante para a transformação do outro, mas não pode transformar o outro, e nem pode ter certeza de que está, de fato, facilitando para que esta possibilidade aconteça. Por isso, tal qual preconiza Kierkegaard, a atitude deste psicólogo é humilde e paciente, guardando uma posição negativa. Portanto no gesto apontado por Kierkegaard o que importa nunca é o texto, ou o estado daquele que busca ajuda, mas a relação estabelecida, a negatividade desta relação, em sua possibilidade de sustentar o espaço da transformação.

\section{Referências}

Brentano, F. (1995) Psychology from an empirical standpoint. New York: Routledge (Original publicado em 1874).

Feijoo, A. M. L. C., Protasio, M. M., Mattar, C. M., Lessa, M. B. M. F. \& Feijoo, E. C. (2013). O pensamento de Kierkegaard e a clínica psicológica. Rio de Janeiro: Edições IFEN.

Husserl, E. (2007). Investigações lógicas: investigações para a fenomenologia e a teoria do conhecimento. Lisboa: Centro de Filosofia da Universidade de Lisboa (Original publicado em 1901).

Justo J. M. (2009). Introdução in A Repetição. Lisboa: Relógio D`Água.

Kierkegaard, S. A. (1986). Ponto de vista explicativo da minha obra como escritor. Tradução de João Gama. Lisboa: edições 70 (Original publicado em 1859).

Kierkegaard, S. A. (2008). La enfermedad mortal. Prólogo e tradução de Demetrio Gutiérrez Rivero. Madri: Editorial Trotta, 2008 (Original publicado em 1849).

Kierkegaard, S. A. (2008b). Postscritpum no científico y definitivo a Migajas filosóficas. Tradução e estudo introdutório de Nassim Bravo Jordán. México: Universidade Iberoamericana (Original publicado em 1846).

Kierkegaard, S. A. (2009) A Repetição. Tradução, Introdução e Notas de José Miranda Justo. Lisboa: Relógio D`Água, 2009 (Original publicado em 1843).

Kierkegaard, S. A. (2010a). O Conceito de Angústia. Tradução e Posfácio de Alvaro Luiz Montenegro Valls. Petrópolis: Vozes (Original publicado em 1844).

Kierkegaard, S. A. (2010b). O desespero humano. Tradução Adolfo Casais Monteiro. São Paulo: Editora Unesp (Original publicado em 1849).

Martins, J. S. \& Valls, A. L. M. (2010). Sobre o conceito de psicologia em Kierkegaard. Cadernos UFS de filosofia Ano 6 - Fascículo XII - Vol. 8 - Julho-dezembro/2010. Sergipe: Departamento de Filosofia da Universidade Federal de Sergipe. Acessível em: http://200.17.141.110/periodicos/cadernos_ufs_filosofia/revistas/ARQ_cadernos_7/jasson.pdf.

Nordentoft, K. (1972/2009). Kierkegaard's psychology. Traduzido por Duquesne University Press. USA, Eugene, Oregon: Wipf and Stock Publishers. 
Myriam Moreira Protasio - Psicóloga. Doutora em filosofia pela Universidade do Estado do Rio de Janeiro (UERJ). Especialista em Psicologia Clínica pelo Instituto de Psicologia FenomenológicoExistencial do Rio de Janeiro - IFEN. Sócia Fundadora, professora, supervisora e coordenadora de Pesquisa no Instituto de Psicologia Fenomenológico - Existencial do Rio de Janeiro (IFEN). Membro da Diretoria da Associação Latinoamericana de Psicoterapia Existencial (ALPE). Pesquisadora pelo Laboratório de Fenomenologia e Estudos em Psicologia Existencial (UERJ).E-mail: myprotasio@yahoo.com.br

Recebido em 08.08.2013 Aceito em 22.05.2014 